\title{
A Misdiagnosed Patient with Recurrent Abdominal Pain: Nutcracker Syndrome
}

\author{
Eylem Kuday Kaykısız1, Ali Fırat Sarp², Ramazan Güven \\ ${ }^{1}$ Clinic of Emergency Medicine, Bitlis State Hospital, Bitlis, Turkey \\ ${ }^{2}$ Clinic of Radiology, Bitlis State Hospital, Bitlis, Turkey
}

\begin{abstract}
Nutcracker phenomenon is characterized by impeded outflow from the left renal vein into the inferior vena cava because of extrinsic left renal vein compression. Because of its rarity and excessive misdiagnosis, we report the case of a 30-year-old female patient who was admitted to the emergency department of our hospital with recurrent left flank and lower abdominal pain andwas diagnosed with nutcracker syndrome. A 30-year-old female patient was admitted tothe emergency department of our hospital with recurrent left flank and lower abdominal pain. Physical examination showed a flaccid abdomen, which was painful onpalpation of the lower portion and left flank, without any signs of peritoneal irritation as well as theabsence of vulvar or lower limb varices. In the work-up, abdominal computed tomography with intravenous contrast was used and revealed compression of the left renal vein between the aorta and superior mesenteric artery. Therefore, the patient was referred to the vascular and endovascular surgery department to evaluate the possibility of a minimally invasive treatment. There is a wide spectrum of clinical presentations of nutcracker syndrome, and the diagnostic criteria are not well defined, frequently resulting in delayed or incorrect diagnosis. From the number of cases reported in the literature, it is obvious that this condition is not very common. Therefore, nutcracker syndrome must kept in mind in patients with recurrent flank and lower abdominal pain duringdifferential diagnosis.
\end{abstract}

Keywords: Nutcracker syndrome, renal vein entrapment, recurrent abdominal pain

\section{Introduction}

Nutcracker phenomenon is characterized by impeded outflow from the left renal vein into the inferior vena cava because of extrinsic left renal vein compression.

Because of its rarity and excessive misdiagnosis, we report the case of a 30-year-old female patient who was admitted to emergency department of our hospital with recurrent left flank and lower abdominal pain anddiagnosed with nutcracker syndrome.

\section{Case Presentation}

A 30-year-old female patient was admitted to the emergency department of our hospital with recurrent left flank and lower abdominal pain. Before this, she was admitted to the emergency department of another hospital and urology policlinic but remained misdiagnosed. The patient had no known disease, medications, and history of surgery, except for caesarean section. Her vital signs were stable. Physical examination showed a flaccid abdomen, which was painful onpalpation of the lower portion and left flank, without any signs of peritoneal irritation as well as theabsence of vulvar or lower limb varices. Findings of initial laboratory tests, including hemogram, biochemistry, and complete urinalysis, were unremarkable. Urinary ultrasonography was performed, and emergent sonopathology was not performed. In the work-up, abdominal computedtomography with intravenous contrast was used and revealed compression of the left renal vein between the aorta and superior mesenteric artery (Figure 1). Therefore, the patient was referred to the vascular and endovascular surgery department to evaluate the possibility of a minimally invasive treatment.

\section{Discussion}

Nutcracker phenomenon, also known as left renal vein entrapment, is characterized by impeded outflow from the left renal vein into the inferior vena cava because of extrinsic left renal vein compression (1). Although the terms nutcracker syndrome and nutcracker phenomenon are sometimes used interchangeably in the litera-

Correspondence to: Eylem Kuday Kaykısız e-mail: eylemkuday@hotmail.com 


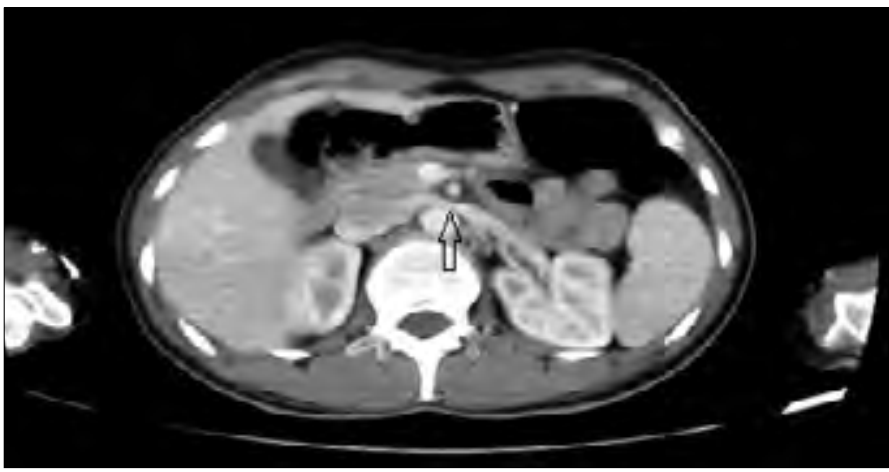

Figure 1. Computed tomography revealed compression of the left renal vein between the aorta and superior mesenteric artery

ture, Shin and Lee (2) have emphasized that the nutcracker anatomy is not always associatedwith clinical symptoms and that some anatomicfindings suggestive of a nutcracker may represent a normalvariant. There is a wide spectrum of clinical presentations and diagnostic criteria are not well defined, frequently resulting in delayed or incorrect diagnosis (3).

Because of uncertainties, some authors have focused on the characteristic anatomic and hemodynamic findings, referring to them asnutcracker phenomenon rather than nutcracker syndrome (4). The earliest pathologic descriptionof this phenomenon was made by Grant in 1937, following which the first clinical report was presented by El-Sadr and Mina $(5,6)$.

The syndrome is manifested by left flank and abdominal pain, with or without unilateral macroscopic or microscopic hematuria. However, it should be noted that hematuria is not always present (7). In our case, recurrent hematuria was present for 10 years but findings of complete urinalysis wereclear by then.

The other common mode of presentation is a symptom complex called "pelvic congestion syndrome," characterized by symptoms of dysmenorrhea, dyspareunia, postcoital ache, lower abdominal pain, dysuria, and pelvic varices (8). Similarly, compression of the left renal vein can cause left renal-to-gonadal vein reflux, resulting in lower limb varices and varicoceles in males (9). When getting a detailed history, our patientsexperienced symptoms suggestive of pelvic congestion syndrome. Systemic manifestations have also been reported in adolescents, including headache, abdominal pain, fainting, and tachycardia mimicking clinical symptoms of an orthostatic disturbance (10).

In summary, the classical manifestations of nutcracker syndrome include flank and lower abdominal pain, unilateral microscopic or macroscopic hematuria, pelvic congestion syndrome, and rarely, varicose manifestations. Its diagnosis is based on history and physical examination as well as basic laboratorytests to exclude other causes of hematuria. Surveillance is appropriate in cases of mild symptoms and either microscopic or insignificantmacroscopic hematuria with no evidence of significant blood loss. Open surgical interventions, although effective, are associated with higher surgical morbidity. If the long-term outcomes remain as good as the short-term results reported to date, stenting (extravascular/intravascular) may become the treatment of choice.

\section{Conclusion}

From the number of cases reported in the literature, it is obvious that this condition is not very common but the prevalence is probably much higher than its diagnosis because the presence of characteristic anatomic changes does not always cause symptoms. Therefore, nutcracker syndrome must kept in mind in patients with recurrent flank and lower abdominal pain duringdifferential diagnosis.

Informed Consent: Verbal informed consent was obtained from patient.

Peer-review: Externally peer-reviewed.

Conflict of Interest: No conflict of interest was declared by the authors.

Financial Disclosure: The authors declared that this study has received no financial support.

\section{References}

1. Rudloff U, Holmes RJ, Prem JT, Faust GR, Moldwin R, Siegel D. Mesoaortic compression of the left renal vein (nutcracker syndrome): case reports and review of the literature. Ann Vasc Surg 2006; 20: 120-9. [CrossRef]

2. Shin JI, Lee JS. Nutcracker phenomenon or nutcracker syndrome? Nephrol Dial Transplant 2005; 20: 2015. [CrossRef]

3. Kurklinsky AK, Rooke TW. Nutcracker phenomenon and nutcracker syndrome. Mayo Clinic Proc 2010; 85: 552-9. [CrossRef]

4. Takahashi Y, Sano A, Matsuo M. An ultrasonographic classification for diverse clinical symptoms of pediatric nutcracker phenomenon. Clin Nephrol 2005; 64: 47-54. [CrossRef]

5. Grant JCB. Method of Anatomy. Baltimore, MD: Williams \& Wilkins; 1937:158.

6. El-Sadr AR, Mina E. Anatomical and surgical aspects in the operative management of varicocele. Urol Cutaneous Rev 1950; 54: 257-62.

7. Takahashi Y, Sano A, Matsuo M. An effective "transluminal balloon angioplasty" therapy for paediatric chronic fatigue syndrome with nutcracker phenomenon. Clin Nephrol 2000; 53: 77-8.

8. d'Archambeau O, Maes M, De Schepper AM. The pelvic congestion syndrome: role of the "nutcracker phenomenon" and results of endovascular treatment. JBR-BTR 2004; 87: 1-8.

9. Little AF, Lavoipierre AM. Unusual clinical manifestations of the nutcracker syndrome. Australas Radiol 2002; 46: 197-200. [CrossRef]

10. Takemura $T$, Iwasa $H$, Yamamoto $S$, Hino $S$, Fukushima $K$, Isokawa $S$, et al. Clinical and radiological features in four adolescents with nutcracker syndrome. Paediatr Nephrol 2000; 14: 1002-5. [CrossRef] 